Research Article Araştırma Makalesi DOI: $10.24011 /$ barofd.954295
Bartın Orman Fakultesi Dergisi, 23(3): 824-836,

15 Aralik/December, 2021
Journal of Bartin Faculty of Forestry p-ISSN :1302-0943

e-ISSN :1308-5875

\title{
Kentsel Açık Yeşil Alanlarda Kullanılan Zehirli Bitkiler Üzerine Bir Araştırma: Rize Kenti Örneği
}

\author{
Ömer Lütfü ÇORBACI ${ }^{1}$, Erdi EKREN ${ }^{2 *}$ \\ ${ }^{1}$ Recep Tayyip Erdoğan Üniversitesi, Mühendislik ve Mimarlık Fakültesi, Peyzaj Mimarlı̆̆ Bölümü, RİZE \\ ${ }^{2}$ Kahramanmaraş Sütçü İmam Üniversitesi, Orman Fakültesi, Peyzaj Mimarlığı Bölümü, KAHRAMANMARAŞ
}

Öz

Kentsel açık yeşil alanların temel unsuru olan bitkilerin kent ekosistemine sundukları birçok önemli faydanın yanı sıra yaşam süreçlerinde çevrelerine bazı olumsuz etkilerinin de olabileceği göz ardı edilmemelidir. Bu olumsuz özelliklerin başında ise bitkilerin çeşitli kısımlarında zehir ihtiva etmesi durumu gelmektedir. Bu çalışma, Rize kentsel açık yeşil alanlarında kullanılan zehirli bitkilerin belirlenmesi amacıyla yürütülmüştür. Çalışma kapsamında Rize kentsel açık yeşil alanlarında kullanıldığı tespit edilen 113 zehirli bitki taksonu; familya, bulunduğu bölge, yaşam formu, yaprak durumu, çiçeklenme zamanı, meyve/kozalak olgunlaşma zamanı ve zehirli kısımları bakımından değerlendirilmiş̧ir. Bu değerlendirme sonucunda, kentsel açık yeşil alanlarda kullanılacak bitkiler seçilirken estetik ve fonksiyonel özelliklerinin yanı sıra zehir ihtiva edip etmediklerinin de göz önünde bulundurulması gereken önemli bir kriter olduğu ortaya çıkmaktadır. Ayrıca, bu bitkilerin peyzaj mimarlığı çalışmalarında kullanımları ile ilgili çeşitli öneriler geliştirilmiştir.

Anahtar Kelimeler: Rize, zehirli bitkiler, kentsel açık yeşil alanlar.

\section{An Investigation on Poisonous Plants Used in Urban Open Green Areas: The Case of Rize}

\begin{abstract}
It should not be ignored that plants, which are the basic elements of urban open green spaces, may have some negative effects on the environment during their life processes as well as many important benefits they offer to the urban ecosystem. At the beginning of these negative features is the fact that it contains poison in various parts of the plants. This study was carried out to determine the poisonous plants used in urban open green areas in Rize. Within the scope of the study, 113 poisonous plant taxa which are used in urban open green areas in Rize were determined and these were evaluated in terms of family, location, life form, leaf condition, bloom time, fruit/cone ripening time and the poisonous parts. As a result of this evaluation, it is revealed that when choosing plants to be used in urban open green areas, whether they contain poison or not is an important criterion to consider as well as their aesthetic and functional properties. In addition, various suggestions have been developed regarding the use of these plants in landscape architecture applications.
\end{abstract}

Keywords: Rize, poisonous plants, urban open green areas. 


\section{Giriş}

Teknolojik gelişmeler, sanayileşme ve ekonomik politikaların sonucu olarak ortaya çıkan ve günümüzün en büyük sorunlarından birisi olan kentleşme birçok çevre sorununun da kaynağı olmuştur. Çevreye yönelik ortaya çıkan bu olumsuzlukları azaltmak için ilk tepkiler, özellikle 1970'lerde başlamış olup halen devam etmektedir (Gündüz ve Dönmez, 2018). Kırsal alanlardan kentlere yapılan göçlerin meydana getirdiği kentsel nüfus artışına bağlı olarak yapılaşma hızının giderek artması, çevresel, sosyal ve ekonomik faydalar ile kaliteli yaşam çevrelerinin oluşturulmasında önemli rol oynayan kentsel açık yeşil alanlara duyulan ihtiyacı gün geçtikçe artırmaktadır (Ekren, 2020; Gülçin 2020). Ülkemizde nüfus yoğunluğunun büyük bir çoğunluğunun kentlerde yaşadığı düşünüldüğünde, kent planlamalarında yeşil alan tasarımları oldukça önemlidir (Özyavuz ve Dönmez, 2016).

Kentsel açık yeşil alanların temel bileşeni olan bitkiler; yaban hayvanları için yaşam ortamı sağlama, mikroklimayı düzenleme, hava kirliliğini azaltma, erozyon kontrolü, gürültüyü azaltma, enerji tasarrufu sağlama, karbon tutma, mekân oluşturma ve kent estetiğine olumlu katkılar sunma gibi birçok fayda sağlamaktadır (Önder ve Akbulut, 2011; Sakıcı vd., 2013; Yılmaz vd., 2017; Düzenli vd., 2018; Gülçin ve Van Den Bosch, 2021). Ancak tüm bu olumlu özelliklerin yanı sıra bitkilerin yaşam süreçlerinde çevrelerine bazı olumsuz etkilerinin ve zararlarının da olabileceği göz ardı edilmemelidir (Şevik vd., 2016; Sarı vd., 2020). Bu olumsuz özelliklerin başında ise bitkilerin çeşitli kısımlarında zehir ihtiva etmesi durumu gelmektedir.

Zehirli bitkiler, yenildiğinde insanlar ve hayvanlar için hastalık veya ölüme neden olabilecek miktarda toksik maddeleri içeren bitkiler olarak tanımlanmaktadırlar (Aplin, 1976). Bu bitkiler tarih boyunca insanların dikkatini çekmiştir. Ancak, eski çağlarda insanlar bu bitkilerle ilgili bilgileri daha çok deneme yanılma yoluyla edinmişlerdir. Zehirli bitkiler ile ilgili ilk liste Bernard Smith tarafından 1905 yılında hazırlanmıştır. Bu çalışmada 255 familyaya ait 11.614 bitki türü incelenmiş ve bu bitkilerin \%1'inin zehirli olduğu tespit edilmiştir (Yılmaz vd., 2006).

Ülkemizde zehirli bitkiler üzerine yapılan ilk çalışma Güley (1953) tarafindan Trabzon ve Samsun yörelerinde gerçekleştirilen ve 72 adet toksik etkiye sahip bitki türünün belirlendiği çalışmadır. Ülkemiz; Avrupa-Sibirya, Akdeniz ve İran-Turan fitocoğrafik bölgeleri ve bu bölgelerin geçiş zonlarını barındırması, çeşitli coğrafi ve iklim özelliklerine sahip olması gibi nedenlerle önemli bir flora çeşitliliğine sahiptir. Ülkemizdeki toplam bitki taksonu sayısı 11.707'dir (Güner vd., 2012). Bu bitkilerden yaklaşık 200’ünün insan ve hayvan sağlığını tehdit edebilecek düzeyde zehir içerdiği bilinmektedir (Bakırel, 1998).

Bitkilerde rastlanan zehirli maddeler çok sayıda ve çeşitlidir. Metabolik faaliyetler sonucu oluşan; alkaloidler, fitotoksinler, glikozidler, oksalatlar, reçine ve tanenler bu zehirli maddelere örnek olarak verilebilir (Y1lmaz vd., 2006). Zehir, bitkilerin farklı kısımlarında ya da tümünde bulunabilir. Bitkilerin ihtiva ettikleri zehir miktarları ise bulundukları coğrafyaya, ekolojik şartlara, bitkinin yaşına ve fizyolojik yapısına göre değişkenlik gösterebilmektedir. Benzer şekilde, insan ve hayvanların bu zehirlerden etkilenme durumları da canlının yaşı, cinsiyeti, genel sağlık durumu ve bağışıklık sistemi gibi faktörlere göre değişiklik gösterebilmektedir (Muca vd., 2012).

Rize ili doğal yapısından kaynaklanan zengin bir bitki örtüsüne sahiptir. Anşin (1980) Rize ilinde 222'si endemik olmak üzere 2239 takson saptandığını belirtmiştir. Çorbacı vd. (2020) ise Rize ili kentsel açık yeşil alanlarında 305 farklı taksonun bulunduğunu tespit etmişlerdir. Bu çalışma, Rize kentsel açık yeşil alanlarında kullanılan zehirli bitkilerin belirlenmesi amacıyla yürütülmüştür. Bu kapsamda tespit edilen bitkilerin zehirli kısımlarının yanı sıra çiçeklenme ve meyve/kozalak olgunlaşma zamanları da belirlenmiştir.

\section{Materyal ve Metot}

\subsection{Materyal}

Araştırmanın ana materyalini Rize kentsel açık yeşil alanlarındaki mevcut bitki varlığı oluşturmaktadır. Bu alanlarda bulunan ve herhangi bir kısmında zehir ihtiva ettiği tespit edilen tüm ağaç, ağaççık, çalı ve yer örtücü bitkiler çalışma kapsamında yer almıştır. Aynı zamanda araştırmanın ana konusunu oluşturan zehirli bitkilere yönelik literatür de araştırma materyali olarak değerlendirilmiştir.

\subsection{Metot}

Araştırma üç aşamadan oluşmuştur. İlk aşamada çalışma kapsamında incelenen kentsel açık ve yeşil alanlar belirlenmiştir. Bu alanlar Tablo 1'de verilmiştir. Alanların belirlenmesinde, alanlar içerisinde zehir ihtiva eden 
bitkilerin bulunması ve takson sayılarının çok olması dikkate alınmıştır. Çalışma kapsamında incelenen kentsel açık ve yeşil alanların konumları ise Şekil 1'de verilmiştir.

Tablo 1. Çalışma kapsamına alınan kentsel açık ve yeşil alanlar

\begin{tabular}{llc}
\hline No & \multicolumn{1}{c}{ Parkın Adı } & Takson Sayısı \\
\hline 1 & 15 Temmuz Demokrasi Park1 & 35 \\
2 & Doğu Park & 13 \\
3 & 28 Ağustos Fetih Park1 & 29 \\
4 & Isırlık Tabiat Park1 & 64 \\
5 & Kale Park1 & 10 \\
6 & Recep Tayyip Erdoğan Üniversitesi Zihni Derin Yerleşkesi & 116 \\
7 & Sahil Camii Parkı & 11 \\
8 & Sahil Parkı/Mesut Yılmaz Parkı & 87 \\
9 & Tanyel Park1 & 7 \\
10 & Tuzcuoğlu Memiş Ağa Parkı & 19 \\
11 & Ziraat Botanik Park1 & 125 \\
12 & Fener Mahallesi Özel Konut Bahçeleri & 10 \\
\hline
\end{tabular}

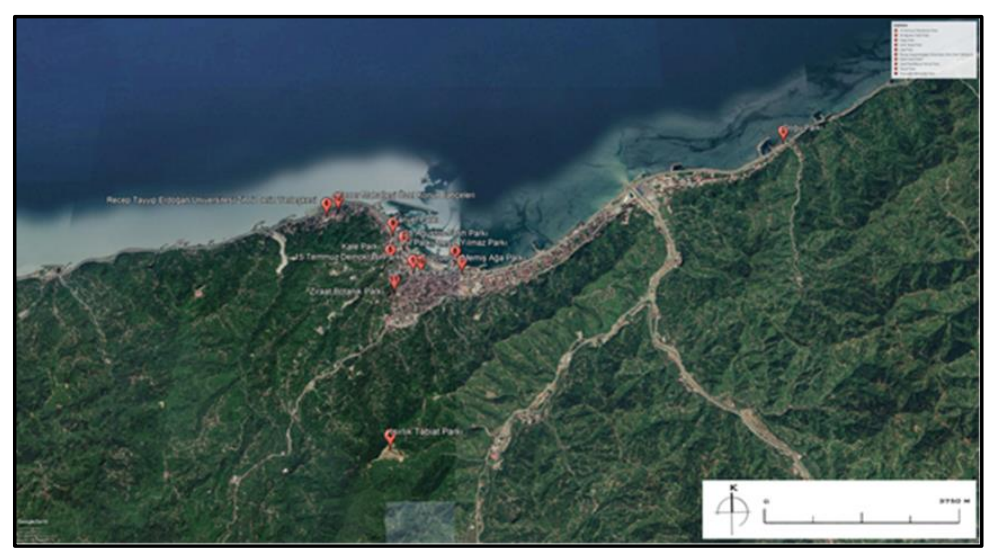

Şekil 1. Çalışma alanlarının konumu (URL-1, 2021)

Araştırmanın ikinci aşamasında çalışma alanlarında bulunan ve zehir içeren bitkiler tespit edilmiştir. Son aşamada ise bu bitkilerin; familyası, bulunduğu bölge, yaşam formu, yaprak durumu, çiçeklenme zamanı, meyve/kozalak olgunlaşma zamanı ve zehirli kısımları ile ilgili değerlendirmeler yapılmıştır. Bu değerlendirmeler yapılırken aşağıda belirtilen kıstaslar dikkate alınmıştır.

Bitkiler yaşam formuna göre; doğal (D), yabancı yurtlu/egzotik (E), kültüre alınmış yabancı yurtlu/egzotik (EK) ve doğallaşmış/yarı doğal (YD) şeklinde sınıflandırılmıştır.

Zehirli bitkilerin zehir içerdikleri önemli kısımlardan bir tanesi yapraklarıdır. Bu nedenle çalışma kapsamında tespit edilen zehirli bitkilerin yaprak durumları incelenmiştir. Bu kapsamda bitki taksonları yaprak durumlarına göre; yaprağını dökmeyen/herdemyeşil (HY), yaprak dökenler (YD) ve geofit (soğan, yumru, rizom, stolon vb.) (G) şeklinde sınıflandırılmıştır. Bitki taksonlarının bulundukları bölgeler Tablo 1'e göre verilmiştir.

Bitkilerin toksin madde içeriği çiçeklenme ve meyve dönemlerinde yoğundur (Gökkür ve Doğan, 2018). Bu nedenle çalışma kapsamında tespit edilen bitkilerin çiçeklenme ve meyve/kozalak olgunlaşma zamanları belirlenmiştir. Bu zamanların numaralandırılması ise şu şekilde yapılmıştır; 1: Ocak, 2: Şubat, 3: Mart, 4: Nisan, 5: Mayıs, 6: Haziran, 7: Temmuz, 8: Ağustos, 9: Eylül, 10: Ekim, 11: Kasım, 12: Aralık.

\section{Bulgular ve Tartışma}

Çalışma kapsamına alınan kentsel açık ve yeşil alanlarda zehir ihtiva eden bitkiler ve bu bitkilerin; familyası, bulunduğu bölge, yaşam formu, yaprak durumu, çiçeklenme zamanı, meyve/kozalak olgunlaşma zamanı ve zehirli kısımları Tablo 2'de verilmiştir. 
Tablo 2. Çalışma kapsamında tespit edilen zehirli bitki taksonları ve özellikleri (Yılmaz vd., 2006; Knight, 2007; Nelson vd. 2007; Wagstaff, 2008; Muca vd., 2012; Kocabaş, 2020)

\begin{tabular}{|c|c|c|c|c|c|c|c|c|}
\hline No & Latince Adı & Familyası & $\begin{array}{l}\text { Bulunduğu } \\
\text { Bölge }\end{array}$ & $\begin{array}{l}\text { Yaşam } \\
\text { Formu }\end{array}$ & $\begin{array}{l}\text { Yaprak } \\
\text { Durumu }\end{array}$ & $\begin{array}{l}\text { Çiçeklenme } \\
\text { Zamanı }\end{array}$ & $\begin{array}{c}\text { Meyve } \\
\text { /Kozalak } \\
\text { Olgunlaşma } \\
\text { Zamanı } \\
\end{array}$ & Zehirli Kısmı \\
\hline \multicolumn{9}{|c|}{ İBRELİ AĞAÇLAR ve AĞAÇÇIKLAR } \\
\hline 1 & Cycas revoluta Thunb. & CYCADACEAE & $1,6,11$ & $\mathrm{E}$ & HY & $5-6$ & $9-10$ & Tüm kısımları \\
\hline 2 & Ginkgo biloba $\mathrm{L}$. & GINKGOACEAE & 6,11 & $\mathrm{E}$ & YD & $5-6$ & $9-10$ & Yaprakları \\
\hline 3 & Juniperus sabina $\mathrm{L}$. & CUPRESSACEAE & 8 & $\mathrm{D}$ & HY & $3-4$ & $8-9$ & Tohumları \\
\hline 4 & Juniperus virginiana $\mathrm{L}$. & CUPRESSACEAE & 8 & $\mathrm{E}$ & HY & $3-4$ & $8-9$ & Kozalakları \\
\hline 5 & Picea orientalis (L.) Link. & PINACEAE & $3,5,8,11$ & $\mathrm{E}$ & HY & $5-6$ & $9-2$ & Gövde kabukları \\
\hline 6 & Picea pungens Engelm. & PINACEAE & 11 & $\mathrm{E}$ & HY & $5-6$ & $9-2$ & Gövde kabukları \\
\hline 7 & Taxus baccata $\mathrm{L}$. & TAXACEAE & 4,6 & $\mathrm{D}$ & HY & $4-5$ & $9-10$ & $\begin{array}{l}\text { Özellikle tohum } \\
\text { olmak üzere yaprak ve } \\
\text { genç sürgünleri }\end{array}$ \\
\hline \multicolumn{9}{|c|}{ GENIŞ YAPRAKLI AĞAÇLAR ve AĞAÇÇIKLAR } \\
\hline 1 & Acer rubrum $\mathrm{L}$. & SAPINDACEAE & 6 & $\mathrm{E}$ & YD & $3-4$ & $11-12$ & Yaprakları \\
\hline 2 & Aesculus hippocastanum L. & SAPINDACEAE & $4,8,9$ & $\mathrm{D}$ & YD & $4-7$ & $9-10$ & $\begin{array}{l}\text { Tüm kısımları (özellikle } \\
\text { tohumları) }\end{array}$ \\
\hline 3 & $\begin{array}{l}\text { *Ailanthus altissima (Mill.) } \\
\text { Swingle }\end{array}$ & SIMORIBACEAE & $6,8,11$ & YD & YD & $5-6$ & $8-9$ & $\begin{array}{l}\text { Yaprakları ve } \\
\text { gövde kabukları }\end{array}$ \\
\hline 4 & Amygdalus orientalis Miller & ROSACEAE & 6 & $\mathrm{D}$ & YD & $3-4$ & $6-7$ & Tohumları \\
\hline 5 & Betula pendula Roth & BETULACEAE & 6,8 & $\mathrm{D}$ & YD & $3-4$ & $6-7$ & $\begin{array}{l}\text { Gövde kabukları } \\
\text { ve yaprakları }\end{array}$ \\
\hline 6 & Buxus sempervirens L. & BUXACEAE & 3,7 & $\mathrm{D}$ & HY & $3-4$ & $11-12$ & Yaprakları \\
\hline 7 & $\begin{array}{l}\text { Caesalpinia gilliesii Wall. ex } \\
\text { Hook. }\end{array}$ & FABACEAE & 12 & $\mathrm{E}$ & YD & $7-8$ & $11-12$ & Meyve ve tohumları \\
\hline 8 & Castanea sativa Mill. & FAGACEAE & 4,11 & $\mathrm{D}$ & YD & $6-8$ & $10-11$ & Meyveleri \\
\hline 9 & Catalpa bignonioides Walter & BIGNONIACEAE & 4 & $\mathrm{E}$ & YD & $5-6$ & $9-10$ & Kök \\
\hline 10 & Cerasus vulgaris Miller & ROSACEAE & 6 & $\mathrm{E}$ & YD & $3-5$ & $6-7$ & Tohumları \\
\hline 11 & $\begin{array}{l}\text { Cinnamomum camphora (L.) } \\
\text { Presl. }\end{array}$ & LAURACEAE & 7 & $\mathrm{E}$ & HY & $6-7$ & $10-11$ & Yaprakları \\
\hline 12 & Cornus mas $\mathrm{L}$. & CORNACEAE & 4,11 & $\mathrm{D}$ & YD & $3-5$ & $6-7$ & Gövde ve dal kabukları \\
\hline 13 & Cotinus coggyria Scop. & ANACARDIACEAE & 6 & $\mathrm{D}$ & YD & $4-6$ & $10-11$ & Yaprakları \\
\hline 14 & Crataegus crus-galli Mill. & ROSACEAE & 6 & $\mathrm{E}$ & YD & $4-5$ & $7-8$ & Tohum \\
\hline 15 & $\begin{array}{l}\text { Eriobotrya japonica (Thunb.) } \\
\text { Lindl. }\end{array}$ & ROSACEAE & $3,4,6,7,8,11$ & $\mathrm{E}$ & $\mathrm{HY}$ & $11-12$ & $4-5$ & Tohum \\
\hline
\end{tabular}


Tablo 2. Devam ediyor.

\begin{tabular}{|c|c|c|c|c|c|c|c|c|}
\hline No & Latince Adı & Familyası & $\begin{array}{l}\text { Bulunduğu } \\
\text { Bölge }\end{array}$ & $\begin{array}{l}\text { Yaşam } \\
\text { Formu }\end{array}$ & $\begin{array}{c}\text { Yaprak } \\
\text { Durumu }\end{array}$ & $\begin{array}{c}\text { Çiçeklenme } \\
\text { Zamanı }\end{array}$ & $\begin{array}{c}\text { Meyve } \\
\text { /Kozalak } \\
\text { Olgunlaşma } \\
\text { Zamanı } \\
\end{array}$ & Zehirli Kısmı \\
\hline 16 & Ficus carica $\mathrm{L}$. & MORACEAE & $4,6,8,11$ & $\mathrm{D}$ & YD & $5-6$ & $8-9$ & Özsuyu \\
\hline 17 & Juglans regia $\mathrm{L}$. & JUGLANDACEAE & 3,4 & $\mathrm{D}$ & YD & $4-5$ & $7-8$ & Yaprakları \\
\hline 18 & Laburnum anagyroides $\mathrm{Med}$. & FABACEAE & 12 & $\mathrm{E}$ & YD & $5-6$ & $8-9$ & $\begin{array}{l}\text { Özellikle } \\
\text { tohumları olmak üzere } \\
\text { tüm bitki }\end{array}$ \\
\hline 19 & Laurus nobilis L. & LAURACEAE & $1,2,4,6,9,11$ & $\mathrm{D}$ & HY & $3-5$ & $6-7$ & Yaprakları ve meyveleri \\
\hline 20 & Liquidambar orientalis Mill. & HAMAMELIDACEAE & $4,10,11$ & $\mathrm{D}$ & YD & $5-6$ & $8-9$ & Yağ1 \\
\hline 21 & Liquidambar styraciflua $\mathrm{L}$. & HAMAMELIDACEAE & $6,10,11$ & $\mathrm{E}$ & YD & $5-6$ & $8-9$ & Yağı \\
\hline 22 & Malus sylvestris Mill. & ROSACEAE & 11 & $\mathrm{D}$ & YD & $4-5$ & $7-8$ & Tohumları \\
\hline 23 & Melia azedarach L. & MELIACEAE & 4 & $\mathrm{E}$ & YD & $4-5$ & $7-8$ & $\begin{array}{l}\text { Yaprak, kabuk, çiçek } \\
\text { ve meyveleri }\end{array}$ \\
\hline 24 & Mespilus germanica L. & ROSACEAE & 6 & $\mathrm{D}$ & YD & $4-5$ & $7-8$ & Genç meyveleri \\
\hline 25 & Platanus orientalis L. & PLATANACEAE & $2,4,5,8,10$ & $\mathrm{D}$ & YD & $7-8$ & $11-12$ & Gövde kabukları \\
\hline 26 & Pittosporum tobira Thunb. Ait. & PITTOSPORACEAE & 8 & $\mathrm{E}$ & $\mathrm{HY}$ & $5-6$ & $8-9$ & Meyve ve yaprakları \\
\hline 27 & Prunus armeniaca $\mathrm{L}$. & ROSACEAE & 6 & $\mathrm{E}$ & YD & $3-4$ & $6-7$ & $\begin{array}{l}\text { Tohumları, yaprakları } \\
\text { ve acı çekirdeği }\end{array}$ \\
\hline 28 & $\begin{array}{l}\text { Prunus cerasifera Ehrh. } \\
\text { 'Pissardii Nigra' }\end{array}$ & ROSACEAE & 8 & $\mathrm{E}$ & YD & $3-4$ & $6-7$ & Tohumları \\
\hline 29 & Prunus cerasus $\mathrm{L}$. & ROSACEAE & 6 & $\mathrm{E}$ & YD & $3-4$ & $6-7$ & Tohum ve yaprakları \\
\hline 30 & Prunus domestica L. & ROSACEAE & $6,8,11$ & $\mathrm{D}$ & YD & $3-4$ & $6-7$ & Tohum ve yaprakları \\
\hline 31 & Prunus laurocerasus L. & ROSACEAE & $\begin{array}{l}1,2,3,4,5,6,7 \\
8,9,10,11\end{array}$ & $\mathrm{D}$ & YD & $4-5$ & $7-8$ & Yaprakları \\
\hline 32 & Punica granatum $\mathrm{L}$. & PUNICACEAE & $4,6,8$ & $\mathrm{D}$ & YD & $4-5$ & $7-8$ & Meyve kabukları \\
\hline 33 & Pyrus communis L. & ROSACEAE & $4,6,8,11$ & $\mathrm{D}$ & YD & $4-5$ & $7-8$ & Tohum \\
\hline 34 & Quercus robur L. & FAGACEAE & 4 & $\mathrm{D}$ & YD & $4-5$ & $10-11$ & Yaprakları ve meyvesi \\
\hline 35 & Rhus coriaria $\mathrm{L}$. & ANACARDIACEAE & 12 & $\mathrm{D}$ & YD & $6-7$ & $10-11$ & Yaprakları \\
\hline 36 & *Robinia pseudoacacia L. & FABACEAE & $4,6,8,11$ & YD & YD & $4-6$ & $8-9$ & $\begin{array}{l}\text { Kök, kabuk içi, } \\
\text { genç yapraklar, meyve } \\
\text { ve tohumlar }\end{array}$ \\
\hline 37 & Salix nigra Marshall & SALICACEAE & 8 & $\mathrm{E}$ & YD & $3-4$ & $6-7$ & Kök \\
\hline 38 & Sambucus nigra $\mathrm{L}$. & CAPRIFOLIACEAE & 11 & $\mathrm{D}$ & YD & $4-7$ & $7-8$ & $\begin{array}{l}\text { Gövde } \\
\text { kabukları, yaprak, } \\
\text { meyve }\end{array}$ \\
\hline 39 & Schinus molle L. & ANACARDIACEAE & 12 & $\mathrm{E}$ & YD & $4-6$ & $8-9$ & Meyveleri \\
\hline
\end{tabular}


Tablo 2. Devam ediyor.

\begin{tabular}{|c|c|c|c|c|c|c|c|c|}
\hline No & Latince Adı & Familyası & $\begin{array}{l}\text { Bulunduğu } \\
\text { Bölge }\end{array}$ & $\begin{array}{l}\text { Yaşam } \\
\text { Formu }\end{array}$ & $\begin{array}{c}\text { Yaprak } \\
\text { Durumu }\end{array}$ & $\begin{array}{c}\text { Çiçeklenme } \\
\text { Zamanı }\end{array}$ & $\begin{array}{c}\text { Meyve } \\
\text { /Kozalak } \\
\text { Olgunlaşma } \\
\text { Zamanı }\end{array}$ & Zehirli Kısmı \\
\hline 40 & Sorbus aucuparia $\mathrm{L}$. & ROSACEAE & 6 & $\mathrm{D}$ & YD & $5-6$ & $8-9$ & Meyveleri \\
\hline \multicolumn{9}{|c|}{ GENIŞ YAPRAKLI ÇALILAR } \\
\hline 1 & Abutilon x hybridum Hort. & MALVACEAE & 10,11 & EK & YD & $4-6$ & $9-10$ & Yaprakları \\
\hline 2 & Aucuba japonica Thunb. & CORNACEAE & 6,11 & $\mathrm{E}$ & HY & $4-5$ & $7-8$ & Meyve ve tohumları \\
\hline 3 & Berberis julianae C.K.Schneid. & BERBERIDACEAE & 4 & $\mathrm{E}$ & $\mathrm{HY}$ & $5-6$ & $8-9$ & Rizomları ve çiçekleri \\
\hline 4 & $\begin{array}{l}\text { Berberis thunbergii DC. } \\
\text { 'Atropurpurea' }\end{array}$ & BERBERIDACEAE & 3,11 & EK & YD & 5 & $8-9$ & Rizomları ve çiçekleri \\
\hline 5 & Berberis vulgaris $\mathrm{L}$. & BERBERIDACEAE & 8 & $\mathrm{D}$ & YD & $5-6$ & $8-9$ & Rizomları ve çiçekleri \\
\hline 6 & $\begin{array}{l}\text { Cestrum elegans (Brongn.) } \\
\text { Schltdl. }\end{array}$ & SOLANACEAE & 11 & $\mathrm{E}$ & YD & $5-6$ & $8-9$ & Tüm kısımları \\
\hline 7 & Cornus sanguinea L. & CORNACEAE & 4 & $\mathrm{E}$ & YD & $4-5$ & $7-8$ & Yaprakları \\
\hline 8 & Daphne odora Thunb. & THYMELAEACEAE & $1,6,11$ & $\mathrm{D}$ & HY & $1-3$ & $6-7$ & Tüm kısımları \\
\hline 9 & Datura stramonium $\mathrm{L}$. & SOLANACEAE & 10 & $\mathrm{E}$ & $\mathrm{HY}$ & $6-8$ & $11-12$ & Tüm kısımları \\
\hline 10 & Euonymus japonicus Thunb. & CELASTRACEAE & $6,8,11$ & $\mathrm{E}$ & HY & $5-6$ & $8-9$ & $\begin{array}{l}\text { Tüm kısımları } \\
\text { (özellikle tohumları) }\end{array}$ \\
\hline 11 & $\begin{array}{l}\text { Hydrangea macrophylla } \\
\text { (Thunb.) Ser. }\end{array}$ & HYDRANGEACEAE & $3,6,8,10,11$ & $\mathrm{E}$ & YD & $7-10$ & $12-1$ & Tüm kısımları \\
\hline 12 & Ilex aquifolium $\mathrm{L}$. & AQUIFOLIACEAE & 4,6 & $\mathrm{D}$ & HY & $6-7$ & $10-11$ & Meyveleri ve yaprakları \\
\hline 13 & Jasminum fruticans $\mathrm{L}$. & OLEACEAE & $4,6,11$ & $\mathrm{D}$ & $\mathrm{HY}$ & $3-4$ & $6-7$ & Çiçekleri \\
\hline 14 & Jasminum sambac (L.) Aiton & OLEACEAE & 6 & $\mathrm{D}$ & HY & $4-5$ & $7-8$ & Tüm kısımları \\
\hline 15 & Lantana camara L. & VERBENACEAE & $1,8,11$ & $\mathrm{E}$ & $\mathrm{HY}$ & $6-8$ & $11-12$ & Meyveleri \\
\hline 16 & Ligustrum vulgare L. & OLEACEAE & 6,11 & $\mathrm{E}$ & YD & $5-6$ & $8-9$ & Meyve ve yaprakları \\
\hline 17 & Lonicera tatarica $\mathrm{L}$. & CAPRIFOLIACEAE & 6 & $\mathrm{E}$ & YD & $5-6$ & $8-9$ & Meyveleri \\
\hline 18 & $\begin{array}{l}\text { Mahonia aquifolium (Pursh) } \\
\text { Nutt. }\end{array}$ & BERBERIDACEAE & 3 & $\mathrm{E}$ & $\mathrm{HY}$ & $4-5$ & $7-8$ & Meyve ve tohumları \\
\hline 19 & Nandina domestica Thunb. & BERBERIDACEAE & $5,6,8,11$ & $\mathrm{E}$ & HY & $4-5$ & $7-8$ & Meyveleri \\
\hline 20 & Nerium oleander L. & APOCYNACEAE & $1,3,4,6,8,11$ & $\mathrm{D}$ & $\mathrm{HY}$ & $6-8$ & $11-12$ & Tüm kısımları \\
\hline 21 & Paeonia suffruticosa Andr. & PAEONIACEAE & 1,11 & $\mathrm{E}$ & YD & $5-6$ & $8-9$ & Gövde kabukları \\
\hline 22 & Pyracantha coccinea M.Roem. & ROSACEAE & 3,8 & $\mathrm{D}$ & HY & $5-6$ & $8-9$ & Meyveleri \\
\hline 23 & Rhododendron ponticum L. & ERICACEAE & $1,6,8,11$ & $\mathrm{D}$ & $\mathrm{HY}$ & $4-5$ & $7-8$ & Yaprak ve çiçekleri \\
\hline 24 & Ricinus communis $\mathrm{L}$. & EUPHORBIACEAE & 12 & $\mathrm{E}$ & YD & $7-9$ & $12-2$ & Tohum, yaprak ve gövde \\
\hline 25 & Ruscus colchicus Yeo & RUSCACEAE & 11 & $\mathrm{D}$ & $\mathrm{HY}$ & $1-4$ & $7-8$ & Tüm kısımları \\
\hline 26 & Schefflera arboricola (Hayata) & ARALIACEAE & 11 & $\mathrm{E}$ & $\mathrm{HY}$ & $7-8$ & $11-12$ & Meyve, sap ve yaprakları \\
\hline
\end{tabular}


Tablo 2. Devam ediyor.

\begin{tabular}{|c|c|c|c|c|c|c|c|c|}
\hline No & Latince Adı & Familyası & $\begin{array}{l}\text { Bulunduğu } \\
\text { Bölge }\end{array}$ & $\begin{array}{l}\text { Yaşam } \\
\text { Formu }\end{array}$ & $\begin{array}{c}\text { Yaprak } \\
\text { Durumu }\end{array}$ & $\begin{array}{c}\text { Çiçeklenme } \\
\text { Zamanı }\end{array}$ & $\begin{array}{c}\text { Meyve } \\
\text { /Kozalak } \\
\text { Olgunlaşma } \\
\text { Zamanı } \\
\end{array}$ & Zehirli Kısmı \\
\hline 27 & Spartium junceum L. & FABACEAE & 6 & $\mathrm{D}$ & YD & $4-5$ & $7-8$ & Tüm kısımları \\
\hline 28 & $\begin{array}{l}\text { Symphoricarpos orbiculatus } \\
\text { Moench }\end{array}$ & CAPRIFOLIACEAE & 4 & $\mathrm{E}$ & YD & $4-5$ & $7-8$ & Meyve \\
\hline 29 & Viburnum opulus L. & ADOXACEAE & 4,8 & $\mathrm{D}$ & YD & $4-5$ & $7-8$ & Meyve \\
\hline \multicolumn{9}{|c|}{ SARILICI VE TIRMANICILAR } \\
\hline 1 & Bougainvillea glabra Choisy & NYCTAGINACEAE & 6 & $\mathrm{E}$ & YD & $5-9$ & $12-2$ & Tüm kısımları \\
\hline 2 & Campsis radicans $(\mathrm{L}$.$) Seem.$ & BIGNONIACEAE & $3,6,11$ & $\mathrm{E}$ & YD & $7-9$ & $12-2$ & Tüm kısımları \\
\hline 3 & Clematis cirrhosa $\mathrm{L}$. & RANUNCULACEAE & 6 & $\mathrm{E}$ & YD & $3-5$ & $8-9$ & Tüm kısımları \\
\hline 4 & Hedera helix $\mathrm{L}$. & ARALIACEAE & 6,11 & $\mathrm{D}$ & HY & $9-10$ & $12-2$ & Tüm kısımları \\
\hline 5 & $\begin{array}{l}\text { Parthenocissus quinquefolia } \\
\text { (L.) Planch }\end{array}$ & VITACEAE & 6,11 & $\mathrm{E}$ & YD & $6-7$ & $11-12$ & Meyveleri \\
\hline 6 & Wisteria sinensis $\mathrm{Sweet}$ & FABACEAE & $2,3,4,6,8,11$ & $\mathrm{E}$ & YD & $4-5$ & $8-9$ & Tüm kısımları \\
\hline 7 & Vinca major L. & APOCYNACEAE & $1,6,8,11$ & $\mathrm{D}$ & $\mathrm{HY}$ & $4-6$ & $9-10$ & Tüm kısımları \\
\hline \multicolumn{9}{|c|}{ SUKKULENTLER } \\
\hline 1 & Agave americana $\mathrm{L}$. & ASPARAGACEAE & 6,11 & $\mathrm{E}$ & HY & $5-6$ & $8-9$ & Tüm kısımları \\
\hline 2 & Opuntia ficus indica (L.) Mill. & CACTACEAE & 11 & $\mathrm{E}$ & HY & $5-6$ & $8-9$ & Tohumları \\
\hline 3 & Yucca filamentosa $\mathrm{L}$. & AGAVACEAE & $4,8,11$ & $\mathrm{E}$ & $\mathrm{HY}$ & $5-6$ & $8-9$ & Dikenleri \\
\hline \multicolumn{9}{|c|}{ YER ÖRTÜCÜLER } \\
\hline 1 & Arum italicum Miller & ARACEAE & $5,6,11$ & $\mathrm{D}$ & HY & $4-5$ & $7-8$ & $\begin{array}{l}\text { Tüm kısımları } \\
\text { (özellikle yumru ve } \\
\text { yaprakları) }\end{array}$ \\
\hline 2 & Brassica nigra (L.) Koch & CRUCIFERAE & $5,6,11$ & $\mathrm{D}$ & HY & $3-5$ & $7-8$ & Meyveleri ve çiçekleri \\
\hline 3 & Cheiranthus cheiri L. & CRUCIFERAE & 6,11 & $\mathrm{E}$ & $\mathrm{HY}$ & $4-5$ & $7-8$ & $\begin{array}{l}\text { Tüm kısımları } \\
\text { (özellikle çiçekleri) }\end{array}$ \\
\hline 4 & Chrysanthemum frutescens $\mathrm{L}$. & COMPOSITAE & 6,11 & $\mathrm{E}$ & $\mathrm{HY}$ & $4-5$ & $7-8$ & Tüm kısımları \\
\hline 5 & Cyclamen coum Miller & PRIMULACEAE & 6,11 & $\mathrm{D}$ & $\mathrm{HY}$ & $1-5$ & $8-9$ & Yumruları \\
\hline 6 & Datura stramonium L. & SOLANACEAE & 11 & $\mathrm{D}$ & $\mathrm{HY}$ & $5-10$ & $1-3$ & Tüm kısımları \\
\hline 7 & $\begin{array}{l}\text { Farfugium japonicum (L.) } \\
\text { Kitam. }\end{array}$ & COMPOSITAE & 11 & $\mathrm{E}$ & $\mathrm{HY}$ & $8-10$ & $1-3$ & Tüm kısımları \\
\hline 8 & Equisetum arvense $\mathrm{L}$. & EQUİSETACEAE & 6 & $\mathrm{D}$ & HY & - & - & Tüm kısımları \\
\hline 9 & Galanthus rizehensis Stern & AMARYLLIDACEAE & 5,11 & $\mathrm{D}$ & $\mathrm{G}$ & $1-4$ & $7-8$ & Soğanı \\
\hline 10 & Genista tinctoria L. & FABACEAE & 5,11 & $\mathrm{D}$ & $\mathrm{HY}$ & $4-7$ & $11-12$ & Tohumları \\
\hline
\end{tabular}


Tablo 2. Devam ediyor.

\begin{tabular}{|c|c|c|c|c|c|c|c|c|}
\hline No & Latince Adı & Familyası & $\begin{array}{c}\text { Bulunduğu } \\
\text { Bölge }\end{array}$ & $\begin{array}{l}\text { Yaşam } \\
\text { Formu }\end{array}$ & $\begin{array}{c}\text { Yaprak } \\
\text { Durumu }\end{array}$ & $\begin{array}{c}\text { Çiçeklenme } \\
\text { Zamanı }\end{array}$ & $\begin{array}{c}\text { Meyve } \\
\text { /Kozalak } \\
\text { Olgunlaşma } \\
\text { Zamanı } \\
\end{array}$ & Zehirli Kısmı \\
\hline 11 & Hyacinthus orientalis L. & LILIACEAE & 6 & $\mathrm{D}$ & G & $3-4$ & $6-7$ & $\begin{array}{l}\text { Tüm kısımları } \\
\text { (özellikle soğanları) }\end{array}$ \\
\hline 12 & Iris germanica $\mathrm{L}$. & IRIDACEAE & 6,11 & $\mathrm{D}$ & $\mathrm{G}$ & $4-5$ & $7-8$ & Tüm kısımları \\
\hline 13 & Mirabilis jalapa L. & NYCTAGINACEAE & 11 & $\mathrm{D}$ & HY & $7-9$ & $1-2$ & Tohumları ve kökleri \\
\hline 14 & Narcissus tazetta L. & AMARYLLIDACEAE & 6,11 & $\mathrm{D}$ & $\mathrm{G}$ & $1-4$ & $6-7$ & Soğanı \\
\hline 15 & Nephrolepis exaltata L. & NEPHROLEPIDACEAE & 11 & $\mathrm{E}$ & $\mathrm{HY}$ & - & - & Yaprakları \\
\hline 16 & Ornithogalum umbellatum $\mathrm{L}$. & LILIACEAE & $5,6,11$ & $\mathrm{D}$ & $\mathrm{G}$ & $3-6$ & $9-10$ & Soğanı \\
\hline 17 & Pelargonium peltatum Ait. & GERANIACEAE & $1,6,11$ & $\mathrm{E}$ & HY & $5-8$ & $11-12$ & Tüm kısımları \\
\hline 18 & Pelargonium zonale L. & GERANIACEAE & $1,6,10,11$ & $\mathrm{E}$ & HY & $5-8$ & $11-12$ & Tüm kısımları \\
\hline 19 & Phytolacca americana $\mathrm{L}$. & PHYTOLACCACEAE & 11 & $\mathrm{D}$ & HY & $6-9$ & $12-2$ & Tüm kısımları \\
\hline 20 & Primula vulgaris Huds. & PRIMULACEAE & $1,6,8$ & $\mathrm{D}$ & $\mathrm{HY}$ & $1-3$ & $6-7$ & Yaprakları \\
\hline 21 & Salvia officinalis L. & LAMIACEAE & 1,6 & $\mathrm{E}$ & $\mathrm{HY}$ & $4-5$ & $8-9$ & Yağl \\
\hline 22 & Salvia splendens $\mathrm{L}$. & LAMIACEAE & $1,6,11$ & $\mathrm{E}$ & $\mathrm{HY}$ & $4-7$ & $10-11$ & Tüm kısımları \\
\hline 23 & Sambucus ebulus L. & CAPRIFOLIACEAE & $5,6,11$ & $\mathrm{D}$ & HY & $7-8$ & $11-12$ & $\begin{array}{l}\text { Gövde } \\
\text { kabukları, yaprak, } \\
\text { meyve }\end{array}$ \\
\hline 24 & Santolina chamaecyparissus L. & ASTERACEAE & $1,6,10,11$ & $\mathrm{E}$ & HY & $5-6$ & $9-10$ & Yaprak ve sapları \\
\hline 25 & Solanum nigrum L. & SOLANACEAE & 11 & $\mathrm{D}$ & $\mathrm{HY}$ & $6-7$ & $11-12$ & Meyveleri \\
\hline 26 & Viscum album $\mathrm{L}$. & LORANTHACEAE & $4,6,8,11$ & $\mathrm{D}$ & $\mathrm{HY}$ & $3-4$ & $6-7$ & Tüm k1sımları \\
\hline 27 & $\begin{array}{l}\text { Zantadeschia aethiopica } \\
\text { L. Spreng }\end{array}$ & ARACEAE & 6,11 & $\mathrm{E}$ & HY & $4-5$ & $7-8$ & Tüm kısımları \\
\hline
\end{tabular}

*Bu taksonlar egzotik olmalarına rağmen Türkiye'de oldukça yaygın olarak kullanılmıș olması ve istilacı özelliklerinden dolayı doğallaşmış/yarı doğal takson olarak kabul edilmektedirler. 
Çalışma alanlarında zehirli özelliklere sahip toplam 113 farklı bitki taksonu tespit edilmiştir. Bu bitkilerin 56 tanesi doğal (Doğal: 54, Yarı Doğal: 2), 57 tanesi egzotik (Egzotik: 55, Egzotik-Kültür: 2) özellik göstermektedir. Bu kapsamda, çalışma alanlarında tespit edilen zehirli bitkilerin \%49,56 doğal ve \%50,44 egzotik bitki olduğu belirlenmiştir.

Çalışma alanlarında tespit edilen zehirli özelliklere sahip bitkiler alanda yeşil kalma süreleri ile insanlar üzerindeki etkilerinin görülebilmesi ve kitle boşluk dengesinin belirlenebilmesi açısından yaprak durumlarına göre değerlendirilmiştir. Bu doğrultuda 54 tane herdemyeşil, 54 tane yaprağını döken bitki taksonu tespit edilmiştir. Ayrıca, belli dönemlerde alanda kendini gösteren 5 adet geofit (soğan, yumru, rizom, stolon vb.) bitki taksonu tespit edilmiştir. Buna göre, çalışma alanlarında zehirli özelliklere sahip bitkilerin; \%48'i herdemyeşil, \%48'i yaprağını döken ve \%4'ü ise geofit olarak belirlenmiştir.

Şekil 2'de görüldüğü üzere zehirli özelliklere sahip 113 bitkinin zehirli kısımları incelendiğinde bu bitkilerden; 33'ünün tüm kısımlarının, 33'ünün yapraklarının, 27'sinin meyvesinin, 23'ünün tohumunun ve 11'inin gövde kabuklarının zehir içerdiği tespit edilmiştir. Ayrıca, tüm kısımlarında zehir bulunan bitkiler hariç 27 bitki taksonunun birden fazla kısmında zehir içerdiği belirlenmiştir.

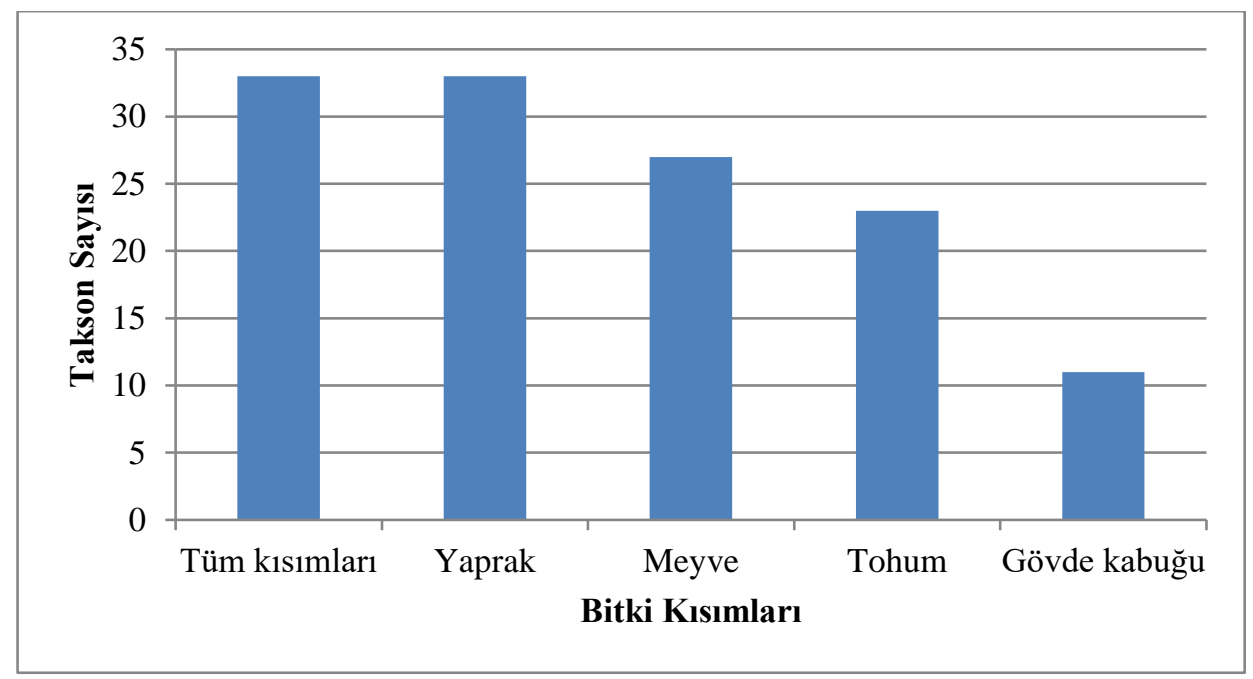

Şekil 2. Zehirli özelliklere sahip olan bitkilerin en çok zehir içeren kısımları

Şekil 3'te çalışma alanlarında en fazla takson bulunan 5 familya verilmiştir. Bu familyalar sırası ile Rosaceae (14 takson), Fabaceae (6 takson), Berberidaceae (5 takson), Caprifoliaceae (4 takson) ve Solanaceae (4 takson)'dir. Çalışma alanlarında Rosaceae familyası en fazla zehirli özellikler gösteren familya olarak ön plana çıkmıştır.

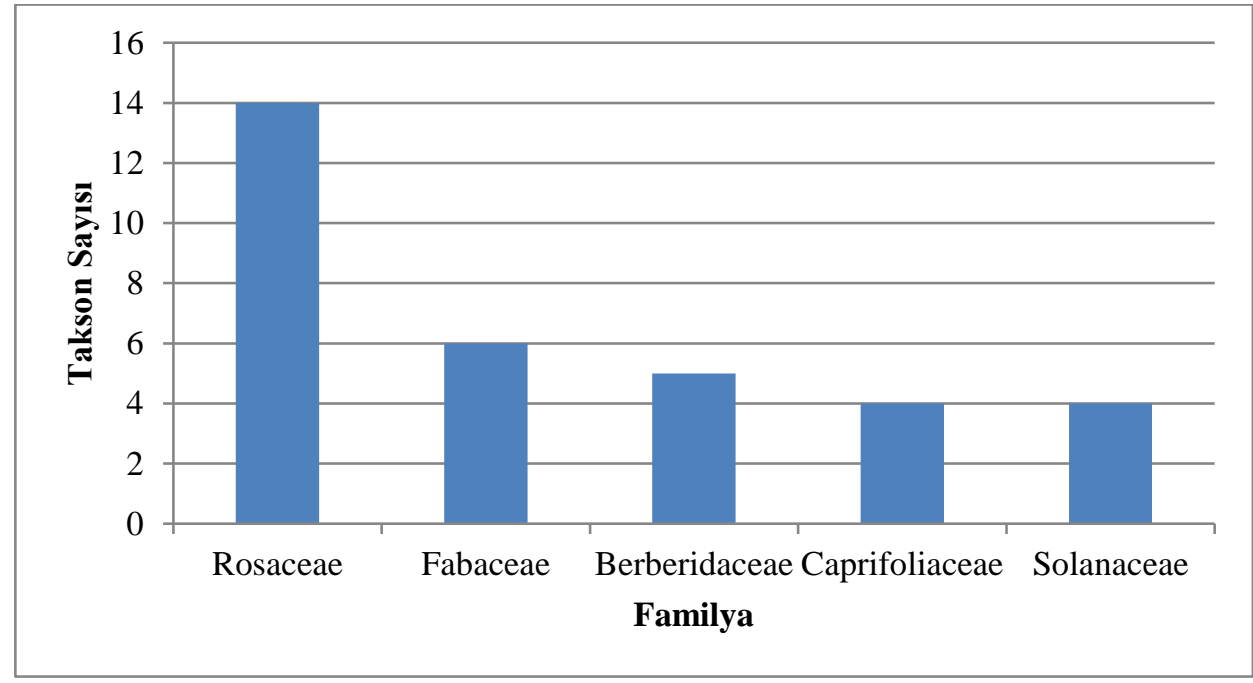

Şekil 3. Çalışma alanlarında zehirli özelliklere sahip en fazla takson bulunan familyalar 
Şekil 4'te çalışma alanlarında tespit edilen bitkilerin çiçeklenme zamanları incelenmiştir. Buna göre bitkilerin en çok çiçeklenme gösterdiği aylar sırası ile; mayıs (71 takson), nisan (59 takson), haziran (48 takson), mart (26 takson), temmuz (26 takson) olarak tespit edilmiştir. Buna göre mayıs ayı çalışma alanlarında tespit edilen zehirli bitkilerin en çok çiçekli olarak gözlemlenebileceği ay olarak dikkat çekmektedir.

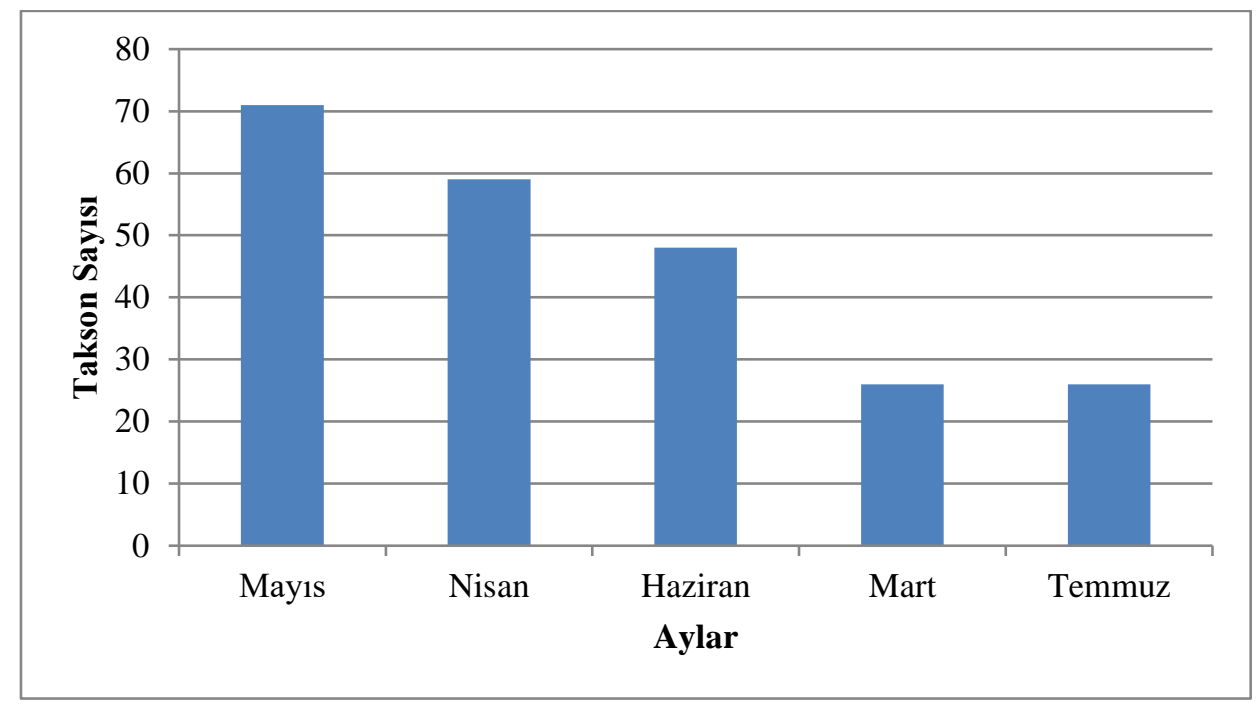

Şekil 4. Zehirli özelliklere sahip bitkilerin en çok çiçekli olarak gözlemlenebileceği aylar

Şekil 5 'te çalışma alanlarında tespit edilen bitkilerin meyve/kozalak olgunlaşma zamanları incelenmiştir. Buna göre bitkilerin en çok meyve/kozalak olgunlaşması gösterdiği aylar sırası ile; ağustos (53 takson), temmuz (42 takson), eylül (38 takson), kasım (23 takson) ve aralık (22 takson) olarak tespit edilmiştir. Buna göre haziran ayı çalışma alanlarında tespit edilen zehirli bitkilerin en çok meyveli/kozalaklı olarak gözlemlenebileceği ay olarak dikkat çekmektedir.

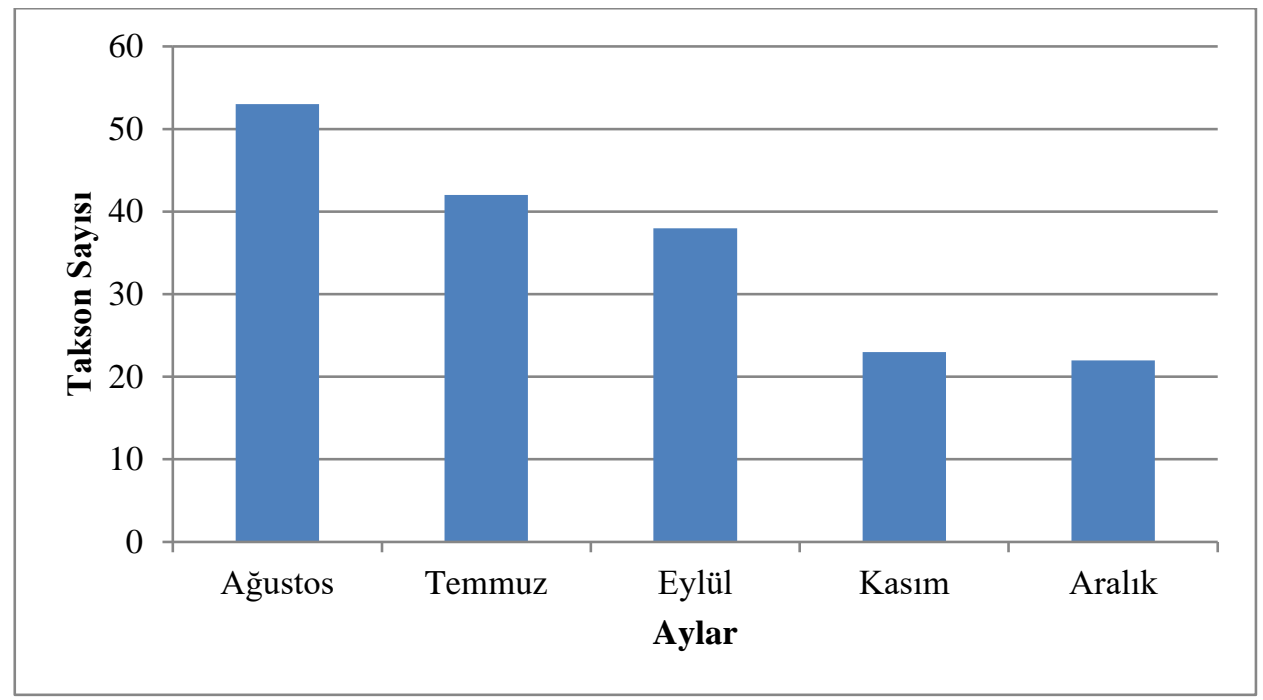

Şekil 5. Zehirli özelliklere sahip bitkilerin en çok meyveli/kozalaklı olarak gözlemlenebileceği aylar

Şekil 6'da görüldüğü üzere zehirli özelliklere sahip bitkilerin en çok bulunduğu kentsel açık yeşil alanlar incelendiğinde bu bitkilerden; 65'inin Ziraat Botanik Parkı'nda, 63'ünün Recep Tayyip Erdoğan Üniversitesi Zihni Derin Yerleşkesi'nde, 31'inin Sahil Parkı/Mesut Yılmaz Parkı'nda, 27'sinin Isırlık Tabiat Parkı'nda, 15'inin 15 Temmuz Demokrasi Parkı'nda bulunduğu tespit edilmiştir. 


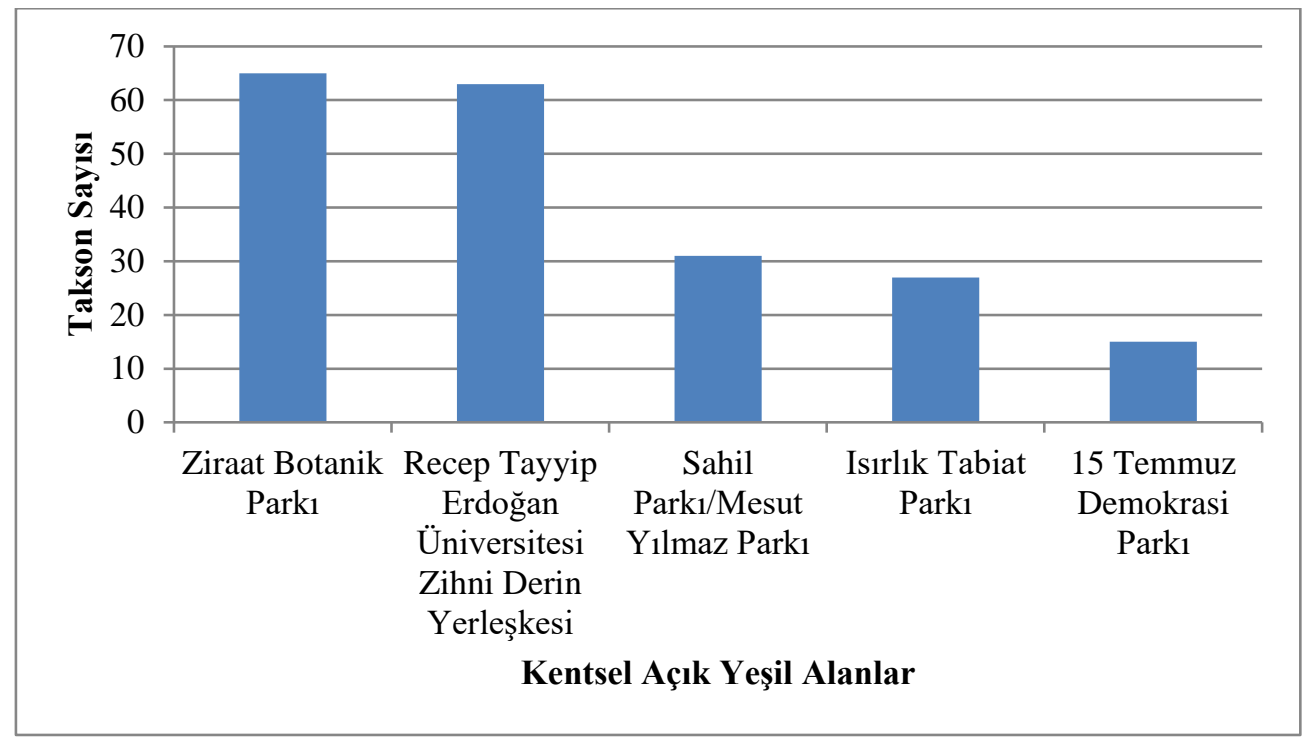

Şekil 6. Zehirli özelliklere sahip bitkilerin en çok bulunduğu kentsel açık yeşil alanlar

\section{Sonuç ve Öneriler}

Kentsel açık yeşil alanların temel unsuru olan bitkilerin kent ekosistemine sundukları birçok önemli faydanın yanı sıra yaşam süreçlerinde çevrelerine bazı olumsuz etkileri de olmaktadır. Bitkilerin farklı kısımlarında ya da tümünde bulunabilen ve metabolik faaliyetler sonucu oluşan zehirli maddeler çok sayıda ve çeşitlidir. Ayrıca, bitkilerin içerdikleri zehir miktarı ve canlıların zehirlerden etkilenme durumları da çeşitli faktörlere göre değişiklik gösterebilmektedir. Zehirli bitkilerin, canlıların vücutlarına olan etkisi ölüme kadar varan sonuçlara neden olabilmektedir. Örneğin, peyzaj mimarlığı uygulama çalışmalarında sıklıkla tercih edilen Taxus baccata L. taksonunun ölümlere sebep olduğu bilinmektedir. Bu takson estetik açıdan meyve güzellikleri ile cezbedici olmasına rağmen, meyvesinin etli kısmı hariç bütün organları zehirli özellik taşımaktadır. Özellikle meyve çekirdeğinin fazla miktarda tüketilmesi ölümle sonuçlanmaktadır (Çorbacı vd., 2016). Taxus baccata L. gibi zehirlilik etkisi güçlü olan bitkilerin kullanımı konusunda dikkatli davranmak gerekmektedir.

Çalışma alanlarında zehirli özelliklere sahip toplam 113 farklı bitki taksonu tespit edilmiştir. Bu bitkilerden; 33'ünün tüm kısımlarının, 33'ünün yapraklarının, 27'sinin meyvesinin, 23'ünün tohumunun, 11'inin gövde kabuklarının ve 8'inin çiçeklerinin zehir içerdiği tespit edilmiştir. Ayrıca, bitkilerin çiçeklenme ve meyve/kozalak olgunlaşma zamanları incelendiğinde bu dönemlerin insanların kentsel açık yeşil alanları en çok kullandığı dönemler olan ilkbahar ve yaz aylarına denk geldiği dolayısıyla insanlar ile bitkiler arasındaki ilişkilerin daha dikkatli sürdürülmesi gerektiği ortaya çıkmaktadır. Kentsel açık yeşil alanlardaki peyzaj tasarım kararlarında daha çok estetik ve işlevsel bitki özelliklerinin dikkate alındığı gözlemlenmektedir (Sarı ve Karaşah, 2020). Ancak kentsel alanlarda kullanılacak bitkiler seçilirken estetik ve fonksiyonel özelliklerin yanı sıra zehir ihtiva edip etmedikleri de göz önünde bulundurulması gereken önemli bir kriterdir. Zehir içeren bitkilerin kullanım alanlarına özen gösterilmelidir.

Doğal ekosistemlerin sürdürülebilirliği açısından kentsel alanlarda yapılacak olan bitkisel uygulama çalışmalarında doğal bitki taksonlarının kullanımı büyük önem taşımaktadır. Çalışma alanında 56 doğal, 57 egzotik bitki taksonu tespit edilmiştir. Yabancı yurtlu/egzotik bitki varlığının fazlalığı doğal ekosistemlerin sürdürülebilirliği açısından büyük riskler taşımaktadır. Doğal bitki kullanımının teşvik edilmesi büyük önem taşımakla birlikte bu bitkilerin doğru kullanılmalarına da özen göstermek gerekmektedir.

Zehirli bitkiler konusunda en hassas olunması gereken grup çocuklardır. Çocuk oyun alanlarının yakınlarında zehirli bitkilerin kullanılmamasına dikkat edilmelidir. Özellikle çocukların dikkatini çekebilecek çiçek ve meyve yapısına sahip olup bu kısımlarında zehir içeren bitkilerin kullanımından kesinlikle kaçınılmalıdır.

Rize il merkezinde yöre halkının, öğrencilerin ve yerli/yabancı turistlerin en çok kullandıkları kentsel açık yeşil alanlar olarak Ziraat Botanik Parkı ve Recep Tayyip Erdoğan Üniversitesi’nin ana kampüsü olan Zihni Derin yerleşkesi ön plana çıkmaktadır. Çalışmanın sonucunda zehirli özelliklere sahip bitkilerin en çok bulunduğu kentsel açık yeşil alanlar da Ziraat Botanik Parkı 65 takson ve Recep Tayyip Erdoğan Üniversitesi Zihni Derin Yerleşkesi 63 takson ile yine bu alanlar olarak belirlenmiştir. Çorbacı vd., (2018) yürütmüş oldukları proje 
kapsamında Ziraat Botanik Parkı ve Zihni Derin yerleşkesinde yer alan bitki taksonlarını etiketlemiş ve bitkilerin birçok özelliğini belirtmiş olmalarına rağmen zehirlilik durumlarını belirtmemişlerdir (Şekil 7.). Zehirli bitkilerin kullanıldığı kentsel açık yeşil alanlarda oluşturulacak etiketlerle bu durumların insanlara aktarılması ve dikkatli olmalarının sağlanması büyük önem taşımaktadır.

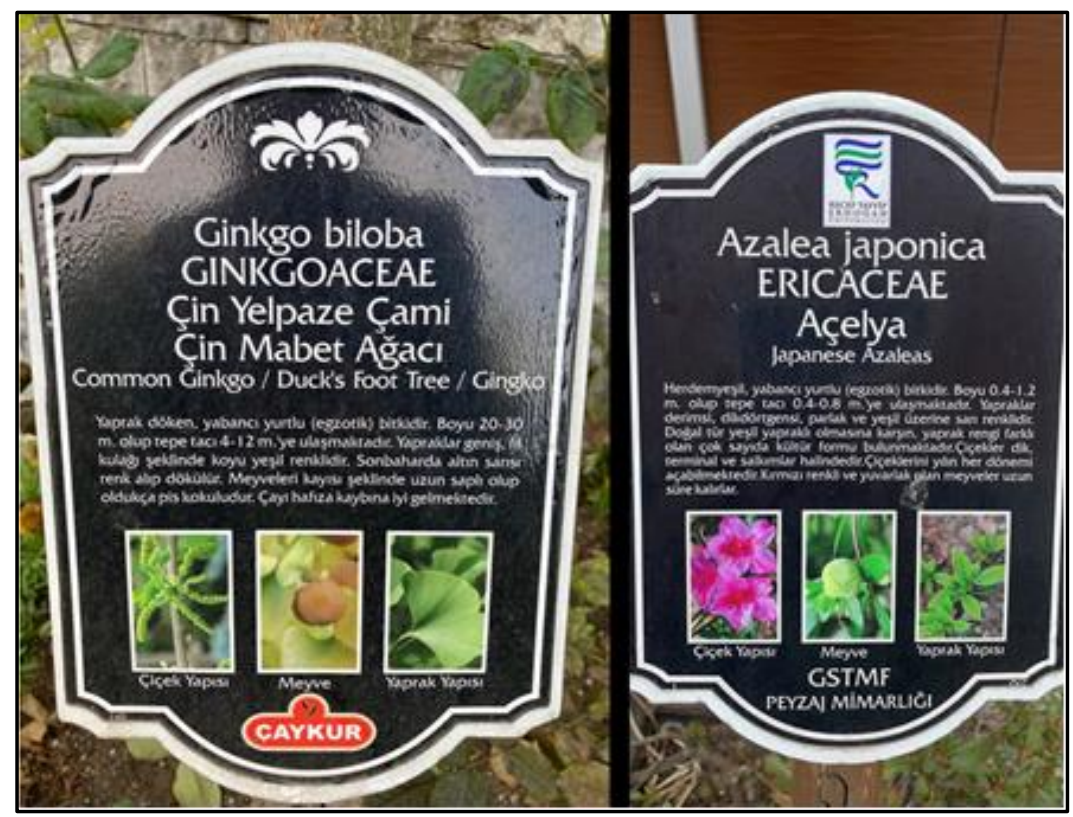

Şekil 7. Bitki etiketi örnekleri

Günümüzde bitkilerin insan sağlığı üzerine birçok önemli katkı sunduğu yapılan bilimsel çalışmalarla ortaya konmaktadır. Örneğin, birçok hastalığın tedavisinde bitkilerden olumlu sonuçlar alınabilmektedir. Ancak bazı bitkilerin farklı kısımlarında içerdikleri zehirli maddeler insanların sağlığ 1 için zararlı olabilmektedir. Bitki zehirlenmeleri genelde bilinçsiz kullanım nedeniyle gerçekleşmektedir. Bu kapsamda, kentsel açık yeşil alanlarda zehirli bitkilerin kullanımının azaltılması veya kontrol altına alınması için gerekli sistematik, fizyolojik ve toksikolojik araştırmaların desteklenmesi ve konu ile ilgili halkın bilgilendirilmesi son derece önemlidir.

Çalışma kapsamında tespit edilen bitki taksonlarının zehirlilik durumları ile ilgili olarak zehirli kısımlarının insanlar üzerindeki etki değerlerinin de belirlenmesi son derece önemlidir. Bazı taksonların zehir etkisi çok yüksekken bazı taksonlarda bu oran düşüktür. Bu kapsamda yapılacak başka bir çalışmada zehirlilik oranları belirlenerek bitki taksonlarının kullanımları hakkında yeni öneriler geliştirilebilir.

\section{Kaynaklar}

1. Anşin, R. (1980). Doğu Karadeniz Bölgesi Florası ve Asal Vejetasyon Tiplerinin Floristik İçerikleri. Doçentlik Tezi, KTÜ Orman Fakültesi, Trabzon. 220 s.

2. Aplin, T.E.H. (1976). Posionous garden plants and other plants harmful to man in Australia. Western Australian Herbarium of Agriculture Bulletin, 3964.

3. Bakırel, T. (1998). Veteriner Toksikoloji Yönünden Trakya Bölgesi’nin Zehirli Bitkileri Üzerine Çalışmalar. Doktora Tezi, İstanbul Üniversitesi Sağlık Bilimleri Enstitüsü, Farmakoloji ve Toksikoloji Anabilim Dalı, İstanbul, $138 \mathrm{~s}$.

4. Çorbacı, Ö.L., Abay, G., Oğuztürk, T. ve Üçok, M. (2020). Kentsel rekreasyonel alanlardaki bitki varlığı; Rize örneği. Düzce Üniversitesi Orman Fakültesi Ormancılık Dergisi, 16(2): 16-44.

5. Çorbacı, Ö.L., Oğuztürk, T. ve Üçok, M. (2018). Atatürk Çay ve Bahçe Kültürleri Araştırma Enstitüsü Müdürlüğü Ziraat Botanik Parkı Bitki Türlerinin Envanterinin Çıkarılması Projesi. ÇAYKUR, Rize.

6. Çorbacı, Ö.L., Sayın, G., Müftüoğlu, V., Çetiner, Z. (2016). Sevimli Katil Taxus baccata L., 6. Peyzaj Mimarlı̆̆l Kongresi “Söylem ve Eylem”, 08-11 Aralık 2016, Antalya, Türkiye.

7. Düzenli, T., Yılmaz, S. ve Tarakçı Eren, E. (2018). Kentsel açık yeşil alanların kullanım türleri ve amaçları. Social Sciences Studies Journal, 4(13): 222-228.

8. Ekren, E. (2020). Yeşil Yol Planlaması: Kahramanmaraş Örneği. Doktora Tezi, Ankara Üniversitesi Fen Bilimleri Enstitüsü, Peyzaj Mimarlığı Anabilim Dalı, Ankara, 262 s. 
9. Gökkür, S. ve Doğan, S. (2018). Ülkemizde bulunan zararlı bitkiler. Apelasyon, 53.

10. Gülçin, D. (2020). Kentsel yeşil alan kalitesinin LIDAR nokta bulutu verileri kullanılarak haritalanması. Türkiye Lidar Dergisi, 2(2): 23-33.

11. Gülçin, D. ve Van Den Bosch, C.C.K. (2021). Assessment of above-ground carbon storage by urban trees using LIDAR data: the case of a university campus. Forests, 12(1): 62.

12. Güley, M. (1953). Samsun ve Trabzon Bölgesi Tıbbi ve Zehirli Bitkilerden Başlıcalarının Farmakodinamik Etkileri ve Tedavideki Önemleri. Ankara Üniversitesi Veteriner Fakültesi Yayınları: Ankara, No:40.

13. Gündüz, B. ve Dönmez, Y. (2018). Üniversite çalışanlarının ekoturizm algısı. Bartın Orman Fakültesi Dergisi, 20(2): 152-162.

14. Güner, A., Aslan, S., Ekim, T., Vural, M. ve Babaç, M.T. (2012). Türkiye Bitkileri Listesi (Damarlı Bitkiler). Nezahat Gökyiğit Botanik Bahçesi ve Flora Araştırmaları Derneği Yayını: İstanbul, $1290 \mathrm{~s}$.

15. Knight, A.P. (2007). A Guide to Poisonous House and Garden Plants. Teton NewMedia: Wyoming, 324 pages.

16. Kocabaş, Y.Z. (2020). Türkoğlu (Kahramanmaraş) ilçe florasında bulunan zehirli bitkiler. Türk Fen ve Sağllk Dergisi, 1(1): 42-51.

17. Muca, B., Yıldırım, B., Özçelik, Ş. ve Koca, A. (2012). Isparta's (Turkey) poisonous plants of public access places. Biological Diversity and Conservation, 5(1): 23-30.

18. Nelson, L.S., Shih, R.D. ve Balick, M.J. (2007). Handbook of Poisonous and Injurious Plants (2nd ed.), Springer: NewYork, 340 pages.

19. Önder, S. ve Akbulut, Ç.D. (2011). Kentsel açık-yeşil alanlarda kullanılan bitki materyalinin değerlendirilmesi; Aksaray kenti örneği. Selçuk Tarım ve Gıda Dergisi, 25(2): 93-100.

20. Özyavuz, M., \& Dönmez, Y. (2016). Konut ve site alanlarında uygulanan peyzaj tasarımlarının yeterliliği üzerine bir araştırma: Tekirdağ kenti. Düzce Üniversitesi Ormancılık Dergisi, 12(2): 108-122.

21. Sakıcı, Ç., Karakaş, H. ve Kesimoğlu, M.D. (2013). Kastamonu kent merkezindeki kamusal açık yeşil alanlarda kullanılan bitki materyali üzerine bir araştırma. Kastamonu Üniversitesi Orman Fakültesi Dergisi, 13(1): 153-163.

22. Sarı, D. ve Karaşah, B. (2020). Future adaptability of urban trees due to the effects of climate change: the case of Artvin, Turkey. Journal of Environmental Science and Management, 23(1): 60-70.

23. Sarı, D., Kurt, U., Resne, Y. ve Çorbacı, Ö.L. (2020). Kent parklarında kullanılan ağaç türlerinin sağladığı ekosistem hizmetleri: Rize Mesut Yılmaz (Sahil) parkı örneği. Anadolu Çev. ve Hay. Dergisi, 5(4): 541-550.

24. Şevik, H., Öztürk, S. ve Çetin, M. (2016). Peyzaj çalışmalarında kullanılan bitkilerin zararlı etkileri (Kastamonu örneği). Düzce Bilim ve Teknoloji Dergisi, 4: 486-492.

25. URL-1 (2021). https://earth.google.com/web/ (30.03.2021).

26. Wagstaff, D.J. (2008). International Poisonous Plants Checklist An Evidence-Based Reference, CRC Press: Florida, 462 pages.

27. Yılmaz, H., Akpınar, E. ve Yılmaz, H. (2006). Peyzaj mimarlığı çalışmalarında kullanılan bazı süs bitkilerinin toksikolojik özellikleri. Süleyman Demirel Üniversitesi Orman Fakültesi Dergisi, A(1): 8295.

28. Yılmaz, S., Düzenli, T. ve Dinçer, D. (2017). Evaluation of factors related to well-being effects of urban green spaces on users. Fresenius Environmental Bulletin, 26: 174-185. 